\title{
Effects of Emotional Intelligence and Creativity Thinking Training on Improving the Emotional Intelligence of Recidivists in Lagos State, Nigeria
}

\author{
Stephens,Oluyemi Adetunji* \\ Department of Psychology of Education, College of Education, University of South Africa \\ Krog, Soezin \\ Department of Early Childhood Education, College of Education, University of South Africa
}

Nel Norma Margaret

Department of Psychology of Education, College of Education, University of South Africa

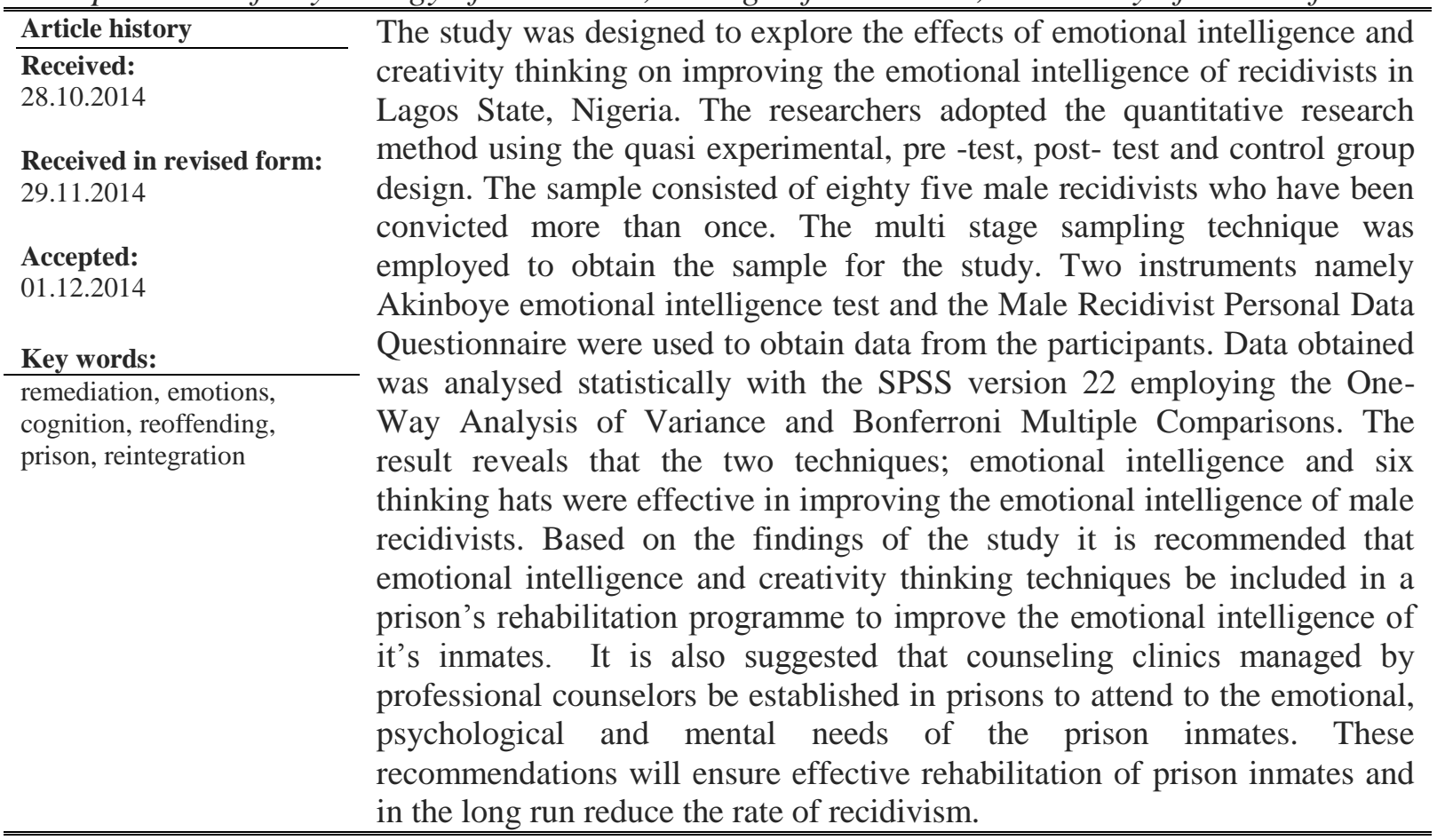

*Correspondence: stephoa@unisa.ac.za +27848785151 


\section{Introduction}

Recidivism is the relapse of criminal activity and is generally measured by a former prisoner return to prison for a new offence. There has been and there is still continuous search by researchers, psychologists and other stakeholders for effective intervention measures that could reduce recidivism. This is because the rate of recidivism is not only high but also increasing. This increase according to Warren (2007) is due to the fact that efforts to control crime through well intentioned offender treatment programmes appeared to be patently ineffective. The rate of recidivism reflect the degree to which released inmates have been rehabilitated and the role that correctional programmes play in reintegrating prisoners into the society (McKean \& Ransford, 2004).

Studies have highlighted various factors that could predispose offenders to reoffend having been punished with imprisonment earlier. Dooley et al. (2014) in a study reports that prison gang membership results in a $6 \%$ increase in recidivism among offenders released from prison operated by Illinois Department of corrections during the month of November 2000. Greco (2012) submits that marital status, age, education, ability to acquire and maintain employment, housing, and familial support as vital to re-entry success. Researchers have also identified inability to meet criminogenic needs of offenders as a major impediment to and a great factor that predispose offenders to reoffend (Andrews \& Bonta, 2010). Criminogenic needs are dynamic factors that are strongly correlated with failure in traditional forms of rehabilitation.

According to the America Community Correction Institute (2014) offenders cycle through the current justice/probation system at the rate of 70\%-90\%.Criminogenic needs which contribute to an individual's risk of recidivating are (i) anti-social attitudes (ii) anti-social beliefs (iii) anti-social friends and peers (iv) anti-social personality patterns (v) high conflict family and intimate relationships (vi) substance abuse (vii) low levels of achievement in school or at work (viii)unstructured and anti-social leisure time. There have also been studies that examined factors that predispose offenders to reoffending in Nigeria. The findings are not different from that of the other countries of the world. Adelola (1998) highlighted the factors to include overcrowding of the prisons, prison systems do not prepare inmates for obtaining jobs to facilitate reintegration after release and prison inmates subculture that gives status to recidivists and tends to foster acceptance based on criminality. The society also contributes to the rate of recidivism as citizens are hostile to ex - convicts and stigmatise them.Tennibiaje (2013) reported from a study conducted among recidivists in prisons in Ekiti State, South West, Nigeria that educational attainment and peer group influence were predictors of an increase in the rate of recidivism among male prisoners.

Furthermore, offenders have been found to have low level of emotional intelligence (Quatler et al. 2010; Seward, 2012; Hayes \& O'Reily in press; Mereya, 2013). Other researchers have also indicated that offenders are deficient in some subcomponents of emotional intelligence such as social problem solving (Mc Murran \& McGuire, 2005) and empathy (Warren, 2007). Emotional intelligence is a social intelligence that enables people to recognise their own, and other peoples' emotions. Moreover, emotional intelligence enables people to differentiate emotions, and to make appropriate choices for thinking and action (Cooper \& Sawaf, 1997; Mayer \& Salovey, 1993). It is an intelligence that may be learned, developed and improved (Perkins or Perkings, 1994; Sternberg, 1996). According to Salovey and Mayer (1990), emotional intelligence includes an 
"ability to monitor one's own and others' feelings and emotions, to discriminate among them and to use this information to guide one's thinking and actions.

In Nigeria, only a few studies have been conducted on emotional intelligence and offenders. These include Stephens \& Badejo (2010a) who evaluated the patterns of emotional intelligence of female offenders. Stephens, Badejo and Gandonu (2010b) considered the emotional intelligence training as an intervention strategy to remediate anti- social behavior of prison inmates from dysfunctional families. In another study Animasahun (2005) examined the effectiveness of emotional intelligence training in fostering positive life skills of Nigeria prison inmates. To the best of the researcher's knowledge there has not been any study to find out the effects of emotional intelligence training on improving the emotional intelligence of recidivists among prisoners Lagos State and Nigeria as a whole. This affords a unique opportunity to explore this.

Emotional intelligence has been found to account for overall success in life, good physical health, mental well-being, developing healthy relationships, conflict resolution skills and effective leadership(Sculderi,2013).Investigators also found that emotional intelligence is an important component of general intelligence, both in terms of behaviour and in the brain (Grohol, 2013). It is also a trait necessary for successfully processing emotional information. Emotional intelligence also promotes pro social behaviour (Cote, DeCelles, McCarthy, Van Kleef \& Hideg, 2011); plays a significant role in peer relations and socioemotional competence (Frederickson, Petrides \& Simmonds, 2011).

In view of the importance of emotional intelligence to human behaviour and the fact that emotional intelligence skills can be learnt (Nelis, Quaidbach, Mikolajczak \& Hansenne, 2009), it has therefore become imperative to explore the effects of emotional intelligence training on the emotional intelligence of recidivists in Lagos State.

On the other hand Mayer et al. (2008) asserts that there is a relationship between emotional intelligence and criminal thinking which needs to be considered and explored as it may counteract efforts of EQ training of recidivists. Criminal thinking is the root of criminal behavior (ClarkPatterson, 2009). Criminal thinking is described by Barbour (2013) as thinking that says it is right to violate the rights of others. Criminal thinking is as a result of a pattern of erroneous thoughts and attitudes that support a criminal lifestyle, denigrates the rights and feelings of others, justifies selfish dangerous and illegal actions (rationalization and denial of responsibility). In addition, criminal thinking allows the offender to continue engaging in criminal activity (Zapf, 2010). The characteristics of criminal thinking are closed channel thinking, victim stance, view self as a good person and lack of interest in responsible performance (Barbour, 2013). Other criminal thinking patterns identified by Zapf (2010) include "meet needs are all that matter", "my behavior are the fault of others", "I have no control over my thoughts or feelings" and "my end justify the means"

Research studies have established that emotions drive our behavior(Goleman,2011)and that there is a relationship between human thought processes and emotion (Akinboye,2006). In addition, Kouhdast, Mahdian \& Naeini(2013) found in their study that emotional intelligence can influence thinking and vice versa. Based on the established relationship between emotion and thinking. With this in mind, the researchers were propelled to employ two treatment packages namely emotional intelligence and Six Thinking Hats training in an effort to ascertain the effectiveness of 
the two strategies in improving the emotional intelligence of male recidivists and to contribute to the quest to find solutions to the increasing rate of recidivism.

The two treatment packages namely emotional intelligence and creativity thinking technique (Six Thinking Hats) were used as intervention strategies to improve the emotional intelligence of male recidivists. The study is designed to explore the effects of these two treatment strategies on improving the emotional intelligence of male recidivists. Emotional intelligence training equips an individual to identify, recognize his emotions and that of others to take appropriate decisions and live a productive life. The second treatment package used in the study is a creativity thinking technique-Six Thinking Hats. Six Thinking Hats is a creativity thinking technique designed by Edward de Bono. It is an important and powerful technique that is used to look at decision from a number of perspectives. This compels an individual to move out of habitual thinking (in this case criminal thinking) and helps an individual get a wider view of situations.

Also as regards the Six Thinking Hats Animasahun (2002) conducted a study that examined the effectiveness of Six Thinking Hats and practical creativity at work in the reduction of psychopathological behavior among adolescents in Nigeria Prison. In another paper Animasahun (2003) investigated the effects of Six Thinking Hats in enhancing the decision making behavior of Nigeria prisoners. Stephens (2012) examined the effectiveness of six thinking hats in reducing recidivism among prisoners in Lagos State. There has not been any study designed to explore the effects of Six Thinking Hats on improving the emotional intelligence of recidivists especially in Nigeria. This is the gap in research that this study intends to fill by exploring the effects of six thinking hats on improving the emotional intelligence of recidivists. The findings of this study would also provide an effective intervention strategy to reduce recidivism.

\section{Statement of the Problem}

There has been continued search for answers to the question "what factors predispose an individual to commit crime" (Ceriaco, 2007). Also there has been a growing concern on why will someone reoffend having been punished with imprisonment. Considering the huge amount of money spent on prison inmates, the threat to personal safety of individuals and increasing insecurity of lives and property, queries are been raised to probe the effectiveness of the rehabilitation programme of the Nigeria Prison Service. Recidivism or reoffending defeats the primary responsibility of the penal system which is to rehabilitate and reintegrate offenders. Since most prison inmates will one day be released from jail, it becomes imperative for research to be conducted to find intervention strategies that could meet the needs of the offenders and deter them from re offending after serving a prison term. Studies have established a link between level of emotional intelligence and an individual's likelihood to reoffend (Seward, 2012). Therefore exploring the effects of emotional intelligence and creativity thinking training on improving the emotional intelligence of male recidivists could help provide an answer to resolve the issue of reoffending This is what this study was set out to do.

\section{Aims Of the Study}

The study was designed to explore the effects of emotional intelligence and creativity thinking training in improving the emotional intelligence of recidivists in Lagos State. Another aim 
of the study was to investigate which of the two intervention strategies will be most effective. The study also was to find out if emotional intelligence of male recidivism could be improved on through training.

\section{Research Hypotheses}

To guide the study two Null hypotheses were formulated and statistically analysed at 0.05 level of significance:

(1) There is no significant difference in the emotional level of participants in the two experimental groups (emotional intelligence and creativity thinking) and their counterparts in the control group.

(2) There is no significant difference in the emotional intelligence level of participants exposed to emotional intelligence and their counterparts exposed to creativity thinking training.

\section{Significance of the Study}

The finding of this study will be of use to remedial and reformatory psychologists as they could employ the two treatment packages (emotional intelligence and creativity thinking) to design intervention strategies that could serve as a preventative and remediative measure to address the issue of recidivism. Counsellors could also adopt the recommendations of this paper as a working tool for intervention programmes to treat anti-social behavior of their clients especially adolescents before they graduate into criminal activities. It could form the basis for designing and introducing emotional intelligence and creativity thinking training into the curriculum of early childhood education as this will help the learners develop pro social behavior which will prevent them from engaging in criminal activities. The study will also open a new vista in research concerning emotional intelligence and creativity training in Nigeria as most studies conducted with these two intervention strategies have been on education aspect and not crime and management of crime.

\section{Methods}

\section{Research Design}

The study adopted the quantitative approach using the quasi experimental research design with a 3 X 2 factorial design. The pre- test post- test control group was employed for the design. The main feature of this design is that a comparison group was selected to compare the treatment group. The data were collected from the pre- test and the post- test both with a treatment package(Six Thinking Hats and emotional intelligence training) and the comparable group that is the control group (Creswell, 2003:116; Schuett, 2006: 210-212). There were two treatment groups (emotional intelligence and creativity thinking technique) and the control group.

\section{Population}

The population consisted of all male prison inmates in Lagos State who have been convicted by a court of law, had served a jail term and are now remanded in prison for committing another offence. 


\section{Sample and sampling technique}

The sample is made up of 85 male recidivists from the three prisons; 25 from Maximum Security Prisons; 30 each from Medium and Ikoyi Security Prisons. Their age range is between 18 and 70 years with a mean age of 36.5 .

The multi stage sampling technique was employed to select the participants. The services of the record officers in the three prisons were employed to get the list containing the names of all prison inmates. The record officers in Nigeria Prisons are charged with the responsibility of keeping all information relating to all prison inmates in their respective prison yard. From the master list, prison inmates were categorized as recidivists and non -recidivists.

At this stage the welfare officer was given the list to assist in assembling recidivists in the prison hall. The researcher addressed the recidivists about the purpose of the study and solicited the cooperation of the recidivists. However, it was clearly stated that participation is voluntary and that no one will be penalized for not participating in the study. Consequently, those who were not interested in the study took their leave. A random table list was made and anyone whose name appeared on the odd number was selected for the study.

\section{Study Research Area}

The study was conducted in Lagos State, Nigeria. The choice of Lagos is predicated on the fact that Lagos is the commercial capital of Nigeria. Lagos State also has the highest number of prisons (5) in Nigeria and the highest prison population (approx. 4000). The research was conducted in three prisons, namely Maximum Security Prisons, Medium Security Prisons and Ikoyi Security Prisons. The three prisons, all male prisons were purposively selected. The criteria for choosing the prisons include being wholly male prisons and accommodate prison inmates who will be able to provide the researcher with valuable, relevant and rich information. The Maximum Security Prisons, Kirikiri, Apapa, Lagos is the most secured in terms of building with high walls and tight security and can house prisoners whose jail term ranges from three (3) years to those sentenced to death.

The Medium Security Prisons, Kirikiri, Apapa, Lagos is of the Ikeja Judicial Division and accommodates prison inmates who have committed minor offences such as petty stealing, wandering as well as prison inmates who are standing trial for heinous crime such as armed robbery and murder but have not been convicted. The Ikoyi Security Prison, Ikoyi, Lagos is in the Lagos Judicial Division of Lagos State. This prison on the other hand is a receiving station, it can only accommodate offenders whose jail term ranges between one (1) day and a maximum of three (3) years.

\section{Instrumentation}

Two instruments were used namely; Akinboye emotional intelligence tests and Male Recidivists Personal Data Questionnaire (MRPQ). Akinboye EQ Tests is a standardized test that is designed to assess various components of emotional intelligence. The emotional intelligence test is also a set of validated tests designed for the use in various areas of human endeavor such as research, consultancy, counseling and education among others (Akinboye, 2006). The test has ten 
(10) different sections, 1-10, it also seeks to gather background information from users. For this study EQ Test Seven was used. The test is a standardized 40- item self -report instrument designed on a 5- point scale to measure respondents' level of emotional intelligence (Akinboye, 2006). It is constructed in the form of statements to which the participants is expected to respond in a continuum. The Face validity of the test was ensured, it also has an internal consistency reliability indicated by a co-efficient alpha $(\alpha)$ of 0.92 There is also an index of construct validity. Convergent construct validity with Emotional Entrepreneurship Test $r=+0.55$. Discriminant construct validity with the Emotional Stress test $\mathrm{r}=-0.87$ and Factor Analysis-Most of the items loaded on Factor one and accounted for about $24 \%$ of the variance. To administer the EQ test, the participants were instructed to read each of the statements carefully and rate the following items by circling the number that reflected their feelings, for example,

- when I see something that I like or want I can't get it out of my head until I get it 12345

- $\quad$ some people make me feel bad about myself no matter what I do 12345

The options given were $5=$ Very true of me; $4=$ Mostly true of me; $3=$ Somewhat true of me; $2=$ Not true of me; $1=$ Not true of me at all

\section{Male Recidivists Personal Data Questionnaire (MRPQ)}

This is a 21-item questionnaire designed by the researcher and was used to obtain personal data of the participants such as age, gender, state of origin, educational background, marital status, family background, occupational status and the criminal history of participants.

\section{Procedure for data collection}

A letter seeking for approval to conduct the study in the prisons was submitted to the Controller of Prisons, Lagos State Command; Zone A, Alagbon, Ikoyi, Lagos. An approval was given by the Controller of Prisons for the researcher to conduct the study at the Maximum Security Prisons, Medium Security Prisons and Ikoyi Security Prisons all in Lagos.

Subsequent on securing the approval, the researcher visited the three prisons with the approval letter and held a meeting with each officer in charge of the three prisons, intimating each of them of the purpose of the study and how the study will be carried out. The officers in charge expressed the hope that the findings of the study will be implemented. The researcher was introduced to the officers in charge of the Welfare and Records department of each prison. The welfare officers in the prisons are in charge of education and other related matters including research while the record officers are charged with the responsibility of admitting, recording and keeping records of all prison inmates in each of the prisons.

The researcher explained the purpose of the study to the record and welfare officers and solicited for their cooperation so as to ensure the success of the research exercise. In each of the three prisons the record officers in each of the prisons provided the researcher with the list of all prison inmates. From the list, the researcher categorized the prison inmates into recidivists and non recidivists. A list of the recidivists was compiled. The compiled list of the recidivists was handed to the welfare officers who called out the recidivists to assemble in the school premises of each of the three prisons. 
In each of the three prisons, the researcher addressed the recidivists, intimating them of the purpose of the study as well as the nature of the study. They were informed that participation in the study is voluntary and that no one will be penalized for not participating. Also, that there will not be any cash reward given for participating in the study. At this point those that are not interested in the study left the hall.

At this stage, the participants were informed by the researcher that the study will be for a period of eight weeks, that there will be three sessions and that each session will last for one and half hours. The participants were assured of the confidentiality of all information they provide in the course of the study. Also, that they could withdraw at any stage of the study and that there will be no financial reward for participating in the study. The researcher promised to provide note books and ball point pens for participants to take down notes in the course of the study. The participants re affirmed their consent by show of hands. The researcher assigned the participants into the two experimental groups and the control group through the dip hat method.

\section{Recruitment of research assistants}

In order to ensure an effective data collection process, two research assistants were employed in each of the three prisons. The research assistants were officials in the three prisons and they are university graduates. The services they provide include assisting in distributing the instruments, helping the participants with filling in and retrieving the questionnaires. They also ensured that the venue is ready before each of the sessions. Before the commencement of the research/data collection, a training programme to explain the rudiments of the study and what their roles will be, was conducted. The training programme in each prison lasted for 1 hour for a period of two days.

\section{Duration of the study}

The study lasted for a period of eight weeks and was in three phases namely, pretest phase, treatment phase and post test phase. The pretreatment phase was conducted during the first week. During this phase participants were assigned to the two treatment groups and the control group through the dip hat method. In addition to this, the pretest scores (emotional intelligence scores) of all the participants were obtained through the administration of the Akinboye emotional intelligence test. The MRPDQ was also administered to obtain the biographic data of participants. The instruments were administered and retrieved in collaboration with the research assistants.

The treatment phase lasted for a period of six weeks, from the second week to the seventh week. The participants in the first treatment group were exposed to emotional intelligence training, the second treatment group to six thinking hats and the control group to teachings on HIV/AIDS awareness.

At the post treatment phase which is the eighth week, the Akinboye emotional intelligence test was administered to all the participants in the three groups. This was to obtain the post test score (emotional intelligence) of participants. The researcher acknowledged the steadfastness of the participants and enjoined them to apply what they had learnt in the course of the study to their daily activities. 


\section{Data Analysis}

The pre-test and post-test emotional intelligence score of all the participants were analyzed statistically at the 0.05 level of significance using the SPSS 22 version. The first hypothesis was analyzed using the Analysis of variance (ANOVA) while the student t-test was used to analyse the second hypothesis.

\section{Results}

Hypothesis 1 which states that there is no significant difference in the emotional level of participants in the two experimental groups (emotional intelligence and creativity thinking) and their counterparts in the control group) was statistically analysed at 0.05 level of significance.

Table 1: Descriptive statistics of the means and standard deviation of the emotional intelligence pretest post score of male recidivists

\begin{tabular}{lllllll} 
Groups & \multicolumn{5}{c}{ Post test } \\
\hline & X Mean & $\mathrm{N}$ & $\mathrm{sd}$ & Y mean & $\mathrm{N}$ & $\mathrm{sd}$ \\
\hline Emotional & 82.96 & 29 & 9.24 & 99.10 & 29 & 10.02 \\
intelligence & & & & & & 10.17 \\
Six Thinking Hats & 78.44 & 29 & 8.23 & 89.00 & 29 & 7.69 \\
Control & 78.92 & 28 & 7.18 & 77.10 & 27 & \\
\hline
\end{tabular}

The result in the table shows the emotional intelligence pre-test scores of participants in the emotional intelligence group (82.96); the Six Thinking Hats group (78.44) and control group (78.92).The post test score of the emotional intelligence group (99.10); six thinking hats (89.00) and the control group (77.10). This indicates that there is an improvement in the emotional intelligence of participants in the emotional intelligence group and six thinking hats group, however there was no improvement in the emotional intelligence of the control group. The next step in the analysis strategy was to investigate performance improvement further (differences): which group/s differ/s from each other. Since three groups were included in the research, the first option would be to do an analysis of variance to investigate whether some of the groups differ from the other. Analysis of variance on the performance improvement variable (the difference variable) can be considered an analysis option because difference is a continuous or scale variable. However, to be able to do a valid and reliable analysis, the pre-requisite of such an analysis - that the three group-variances are homogeneous - has to be investigated (otherwise a non-parametric analysis for the comparison of means have to be used) Levene's test for homogeneity of variances of the three groups are reported below (Table 2),to test whether group-variances for the three groups condition, can then compare differences gom; where/ which look

Table 2: Levene's test for the homogeneity of group variances $H_{4}:$
\begin{tabular}{llll} 
Levene Statistic & df1 & df2 & Sig. \\
& & & \\
\hline 1.023 & 2 & 82 & .364 \\
\hline
\end{tabular}

Since the probability of the test statistic associated with Levene's test (1.023) is greater than 0.05 , the test cannot be rejected, therefore it can be assumed that group variances are homogeneous and that the homogeneity assumption of analysis of variance is satisfied and that results of an analysis of variance will be reliable and valid 
Table 3 below reports on the results of the analysis of variance: Since the probability associated with the F statistic for the effect of groups ("between groups") are less than 0.001 , the assumption can be made that the null hypothesis of no difference between the performance-improvement means (the difference means) of the three groups can be rejec

Table 3: One-way analysis of variance on the performance-improvement measure (difference measure) to test the significance of groups (control, EI, and CT)

\begin{tabular}{llllll}
\hline & Sum of Squares & df & Mean Square & F & Sig. \\
\hline Between Groups & 4441.859 & 2 & 2220.930 & 21.499 & .000 \\
Within Groups & 8470.917 & 82 & 103.304 & & \\
Total & 12912.776 & 84 & & & \\
\hline
\end{tabular}

The analysis of variance test only indicate that group-effect is statistically significant: it does not indicate which group/s differs from which group/s. The Bonferroni multiple comparisons of means test reported in Table 5 below was therefore also conducted to test which group's mean (for improvement) differ statistically significantly from which. The differences (between group means) indicated in the second column are evaluated against a measure, the "least significant difference" or lsd value and indicated that the improvement-mean of the control group (group 3) differs statistically significantly from that of the EI and CT groups (groups 1 and 2). The test also indicate that the improvement means of EI and CT differ statistically significantly from one another. Therefore the three groups differed significantly from one another: the EI group improved the best $($ mean $=16.1379)$; then group CT $($ mean $=10.5517)$ ) and then the control group indicate no improvement $($ mean $=-1.3704)-$ which actually signifies regress in performance.

Table 4: Bonferroni multiple comparisons of means test for three improvement means

\begin{tabular}{|c|c|c|c|c|c|c|}
\hline $\begin{array}{l}\text { (I) participants in } 3 \\
\text { groups }\end{array}$ & $\begin{array}{l}(\mathrm{J}) \\
\text { participants } \\
\text { in } 3 \text { groups }\end{array}$ & $\begin{array}{c}\text { Mean } \\
\text { Difference (I- } \\
\text { J) }\end{array}$ & Std. Error & Sig. & $\begin{array}{l}\text { 95\% Confi } \\
\text { Lower } \\
\text { Bound }\end{array}$ & $\begin{array}{l}\text { dence Interval } \\
\text { Upper Bound }\end{array}$ \\
\hline \multirow[t]{2}{*}{1} & 2 & 5.58621 & 2.66916 & .118 & -.9374 & 12.1099 \\
\hline & 3 & $17.50830^{*}$ & 2.71814 & .000 & 10.8649 & 24.1517 \\
\hline \multirow[t]{2}{*}{2} & 1 & -5.58621 & 2.66916 & .118 & -12.1099 & .9374 \\
\hline & 3 & $11.92209^{*}$ & 2.71814 & .000 & 5.2787 & 18.5654 \\
\hline \multirow[t]{2}{*}{3} & 1 & $-17.50830^{*}$ & 2.71814 & .000 & -24.1517 & -10.8649 \\
\hline & 2 & $-11.92209^{*}$ & 2.71814 & .000 & -18.5654 & -5.2787 \\
\hline
\end{tabular}

*. The mean difference is significant at the 0.05 level

The second hypothesis which states that there is no significant difference in the emotional intelligence level of participants exposed to emotional intelligence and their counterparts exposed to Six thinking hats training was statistically analyzed at 0.05 level of significance using the independent t-test.

Table 5: Difference in the emotional intelligence post test score of male recidivists

\begin{tabular}{lllllllll}
\hline Group & $\mathrm{N}$ & $\mathrm{X}$ & $\mathrm{sd}$ & $\mathrm{Df}$ & $\mathrm{sig}$ & $\mathrm{t}$ - cal. & t-tab \\
\hline $\begin{array}{l}\text { Emotional } \\
\text { intelligence }\end{array}$ & 29 & 99.10 & 10.02 & & & & & \\
$\begin{array}{l}\text { Six thinking } \\
\text { hats }\end{array}$ & 29 & 89.00 & 10.17 & & & & & \\
\end{tabular}


The result in table 5 shows that the $\mathrm{t}$ calculated value of 3.810 was greater than t.cal. The hypothesis is not accepted. This implies that there is a significant difference in the emotional intelligence post score of male recidivists. Furthermore, participants in the emotional intelligence group has a higher mean score (99.10) compared to that of the Six Thinking Hats group (89.00). This means that the emotional intelligence training was more effective in improving the emotional intelligence of recidivists than the Six thinking hats.

\section{Discussion}

The first hypothesis which states that there is no significant difference in the emotional level of participants in the two experimental groups (emotional intelligence and Six thinking hats) and their counterparts in the control group) was statistically analysed at 0.05 level of significance. This hypothesis was not accepted based on the result of the analysed data. The participants who were exposed to emotional intelligence training recorded highest improvement followed by those who were exposed to Six Thinking Hats group. The control group regressed did not make any improvement. The finding confirms that emotional intelligence could be learnt (Davies,2010) and that this could be done through training, practice and reinforcement. Nelis et al. (2009) also confirms that emotional intelligence can be learnt. This finding is also in agreement with Animasahun (2005); Stephens (2006); Stephens \& Badejo (2010) who in their different studies employed emotional intelligence training to improve the emotional intelligence of prisoners and correct some of their maladaptive behavior. The result of this study also reiterated the position of Goleman (2006) who suggest that emotional intelligence should be taught in the prison. Dixit (2008) also recommended that various governments should create prisons that teach selfawareness, self-control, empathy, emotional regulation and thinking before action. Also that the emotional intelligence of participants exposed to Six Thinking Hats training improved confirms the finding of Akinboye $(2003,2006)$ who established a relationship between creativity training and emotional intelligence.

The second hypothesis which states that there is no significant difference in the emotional intelligence level of participants exposed to emotional intelligence and their counterparts exposed to six thinking hats training was not accepted. There is a significant difference this could be because emotional intelligence training directly focused on the emotions of the participants while the six thinking hats as a technique addresses the changing of the thinking pattern of participants. This study established a relationship between emotions and cognition. It also confirms the findings of Akinboye $(2003,2006)$ who reports a link between emotional intelligence and creativity thinking.

\section{Recommendations}

The following recommendations are made on the basis of the findings of this study: Firstly, it is recommended that psychologists should design programmes to identify the risk assessment needs of offenders that could predispose them to reoffending. These needs may include deficiency in their emotional intelligence level and criminal thinking, among others. Based on the risk assessment needs, specific intervention programmes should be designed to meet the identified needs. Secondly, since the emotional intelligence and creativity thinking training improved the emotional intelligence of participants, it is suggested that emotional intelligence and creativity thinking training be conducted for all offenders both first timers and reoffenders in the 
prisons.Other positive life skills such as anger management, problem solving skills among others should be included in the rehabilitation programme. Substance abuse treatment programmes should also be included in the rehabilitation programme. It is also suggested that further studies be done on using other positive life skills to reduce the rate of recidivism.

\section{References}

Akinboye J.O (2003). Creativity, Innovation and Success. Ibadan: Stirling Holden Publishers (Nig) Ltd.

Akinboye, J.O., (2006). Manual for Users of EQ Tests. Ibadan: CYFO Behaviour Services.

Animasahun RA 2002. Effect of Six Thinking Hats and Practical Creativity in the reduction of psychopathological behaviour among some adolescents in Nigeria prisons. Ibadan Journal of EducationalStudies, 2(2): 573-587.

Animasahun RA 2003. The effect of Six Thinking Hats in Enhancing the Decision Making Behaviour of Nigeria Prisoners. Nigerian Journal of Applied Psychology, 7(2): 66-79

Animasahun, R. A. (2005). Effectiveness of Emotional Intelligence Training in Enhancing the Positive Life Skills of Nigerian Prison Inmates. A paper presented at the Faculty of Education University of Ibadan, Ibadan.

Ceriaco,C.B(2007).Factors influencing the commission of crime. Available at https//www.scribd.com/doc/1910875/causes of crime on October 21,2014

Cote, S., DeCelles,K.A.,McCarthy, J.M.,Van Kleef,G. A \&Hideg,I(2011).The Jekyll and Hide of emotional intelligence. Emotion regulation knowledge and interpersonalty deviant behavior .Psychological Science 22(8) 1073-1080

Creswell, J.W (2003).Research Design: Qualitative, quantitative and mixed methods approaches $\left(2^{\text {nd }}\right.$ eds) Thousand Oaks, CA: Sage

Davies, S. (2010) Leadership in Action, Emotional intelligence and Leadership. Egon Zehnder International. Available at www.ceoforum.com/. Retrieved on24/09/2010

Dooley, B.D., Seals A., \& Skarbek D (2014). The effect of prison gang membership on recidivism. Journal of Criminal Justice 42 (2014):265-275.

Frederickson, N., Petrides, K.V., Simmonds,E (2011).Trait emotional intelligence as a predictor of socio emotional outcomes in early adolescents. Personality and Individual Differences 52(2012) 323-328.

Goleman D(2011). Working with emotional intelligence. Random House Publishers:NY

Greco,C (2012). Reducing recidivism: Whose responsibility is it? Available at http//www.correctionsone.com/re-entry-and-recidivism/articles/5099199-Reducingrecidivism-Whose-responsibility-is-it/.Retrieved on October 2, 2014.

Grohol,J.M (2013). Importance of emotional intelligence validated. Available at psychcentral.com/news/2013/01/24.Retrieved on October 3,2014.

Haye J.M\& O'Relly G (in press). Psychiatric disorder, IQ and emotional intelligence among adolescent detainees: A comparative study. Legal and Criminological Psychology DOI:10.IIII/j. 2044-8333.2011.0207

Kouhdast,R.N,Mahdian,M.J\&Naeini,M.A(2013). The relationship between emotional intelligence and thinking styles in male and female students in Tehran,Iran.International Journal of Learning and Development.3(3)110-119. 
Mayer J.D.,Salovey, P\& Caruso,D.R (2008) Emotional intelligence: new ability or eclectic traits? American Psychologist 63:503-517.

Mayer, J.D., \& Salovey, P (1993). The intelligence of emotional intelligence: Intelligence 17:44342

McMurran, M \& McGuire J (2005). Social problem solving and offending: evidence, evaluation . John Wiley\& Sons: Chi Chester, UK.

Megreya AM 2013.Criminal thinking style and emotional intelligence in Egyptians offenders. Criminal Behaviour and Mental Health 23:56-71.

Nelis,D.,Quaidbach,J., Mikolajczak, M\& Hansenne, M(2009).Increasing emotional intelligence(How) is it possible? Personality and Individual Differences 47:36-41. Organizations.

Perkings,D(1994).Outsmarting: The emerging science of learnable intelligence. New York: The Free Press

Quatler P, Ireland J \& Gardner K (2010).Exploratory and confirmatory factor analysis of the Schutte self - report emotional intelligence scale (SSREI) in a sample of offenders. British Journal of Forensic Practice, 12:43-51.

Salovey,P\& Mayer,J.D (1990).Emotional intelligence. Imagination, Cognition and Personality, 9:185-211.

Schutt ,R.K(2006) Investigating the social world: The process and practice of research( $5^{\text {th }}$ eds $)$ Thousand Oaks, CA: Sage

Scuderi,R (2014)Emotional intelligence-Why it is important. Available at www.lifehack.org.Retrieved on October 3, 2014.

Stenberg,RJ(1996).Successful intelligence. New York: Simon Schutter.

Stephens O.A. and Badejo, A.O. (2010a). Emotional intelligence training as an intervention strategy in remediating anti-social behaviour of some selected prison inmates from dysfunctional families. The Counsellor, 27, 29-37.April 2010.

Stephens, O, Badejo, A. O and Gandonu, M.B. (2010b). A study of the patterns of Emotional Intelligence of Female offenders; Implication for Counselling; The Counsellor, 28, 1320.August 2010 